\title{
Effect of Migration on Household and Left Behind Family Members: Case of Kyrgyzstan
}

\author{
Bekhzod Egamberdiev (Tashkent State University of Economics, Uzbekistan) \\ Dilshod Zoirov (Westminster International University in Tashkent, Uzbekistan)
}

\begin{abstract}
More than billion international and internal migrations around the world as well as the relationship between migrant and its family members have been one of the most discussed policy questions for several years. Main purpose of the paper is to examine the impact of labor migration on household, in order to address arising social problems due to the migration of family member. To find the impact, it was used secondary data named "Life in Kyrgyzstan" which is research based, open access and multi-topic longitudinal survey of households in Kyrgyzstan. It includes more than 3000 households which were recorded from 2010 to 2013. The result of the research is: there is a positive impact of remittances on child education, while negative on nonfood spending. Also housing condition is directly related with migration and significant impact can be seen in terms of facilities and type of household. Based on findings, it was provided some policy recommendations to simplicity of the social and other issues in the household of migrant's. One of the recommendations is: The Government of Kyrgyzstan should pay high attention on keeping citizens inside the country and should consider about shifting its policies which encourage labor migration, instead it should pay more attention on development of small and medium enterprise supporting method, which actually helps to create several number of job positions.
\end{abstract}

\section{Introduction}

In 21 st century more and more countries paying more attention to the level of migration. More than a billion of people around the world live and work outside their birth countries. Many rich societies and emerging economics are facing rapid population aging, while work aged people have been continuing to grow in other low income countries. Labor migration can be seen as economically beneficial not only for households but also to the whole economy of the country through remittances (Adams, R. H. 2011). On the other hand, separation of family members might have adverse influence on education, health and labor supply response of non-migrant members of the family. In fact, migration mostly stands for changing the residence of some individuals. They can move from one country to another country. The place of movement can be chosen voluntarily based on the purpose such as looking for the better opportunities in terms of life and financial condition. Second is escaping the current negative or dangerous situation of their own country. Nevertheless, main effect of the migration can be seen in family's lifestyle. Some people leave their families while some bring them to the "new" place. The purpose of this paper is analyzing whether there is an effect of migration on household condition or not. If the answer is "YES" the analyses should reveal the advantages and disadvantages of migration.

\section{Literature Review}

Migration is a significant and multidimensional element of population process. Newell, Colin (1988, 82p) considered migration as one of the important principles of change in population. The world population have been growing or declining with the directly connection of birth and death. Over time, movement of individuals promote more than just the original number of people coming to new area, because children and grandchildren which are born in immigrant population add majority times to the initial number of population of the country and nation. For instance, most Americans are people who arrived to US over the past 150 years. Only minority of population is related with American Indians who actually were there when the European homesteaders arrived in 1600s.

Goldscheider, C (1971) defines migration as "any permanent change in residence". It includes the movement of all activities from one place to another place. Current idea was also supported by Week, J.R(1989). Their view to migration are based on the mobility of individuals from origin place to place where they want to shift. These places have political barriers, which are crossed by individuals during their movement for an unknown period, as they did not mention any information about long or short time of permanent change. On the other hand, migration can be seen as a change of place pf living for almost a long period (Ghosh,1989). Moreover, he stated leaving one place due to the new area for temporary period is not considered as a migration from the demographic point of view. Therefore, it can be argued whether the length of time plays an important role in classification of migration.

Migration is the "perceptible and simultaneous shifts in both spatial and social locus" (Zelinsky, 1971). He mostly refers to territorial movements and stated not all types of movement are classifying as a migration. He stated, migration means long-lasting change of residence and therefore commuters, holidaymakers and student moving between home and university is an exception.

According to Shrivastava, (1983) migration implies a permanent or at least for some period of time, moving for a place far from their home. Also he mentioned, if an individual is staying at a place but was not born in that 
particular place, they are considered as migrants. However, Newman and Matzke have critically argued about meaning and understanding of migration. They stated, most classifications of migration mostly focus on the idea of perpetual or semi-permanent variation of place to differentiate migration from circulation. The circulation does not cover the change of residence and includes daily movements such as going for work, vacation and shopping trips. Moreover, "there is no unanimity over the meaning of migration" though many consider it as movement involving a change of residence of substantial duration (Clarke, 1965). Based on this view, temporary movement of nomads, tourists and the international drivers, which justifies their exclusion because of the absence of appropriate term, which may cover the numerous spatial of movements of population. After revising these views there might be a question, is working or going outside of people is equal to migration or not.

In general, in many cases there is neither a positive or negative influence of migration on several factors. Migration is a decision that impacts the welfare of the household, the home community, and in the end the whole economy in various ways (Azam and Gubert 2006). The welfare implications of migration happen frequently although it is not always positive. Main advantage of migration is increasing the poverty of incomes from remittances, which can be used to investment of starting a new business, enhance the knowledge by international resources and also it can be useful for improvement of health care. However, as everything has two sides, the migration is not an exception and not all effects of migration are positive. More and more the exploitation of migrant became popular due to the unconscionable recruiters. Furthermore, leaving the members of family behind and isolation from them can be stressful for migrants.

Migration and remittances have both direct and indirect effects on the welfare of the population in the migrant sending countries. A cross-country study of 71 developing countries found that a 10 percent increase in per capita official international remittances will lead to 3.5 percent decline in the share of people living in poverty (Adams \& Page 2005). Evidence from Latin America, Africa, South Asia and other regions exemplified that remittances increase the financial condition and has indirect effect on stimulation of economic activity (Adams 1991, Lachaud 1999, Fajnzylber \& Lopez 2007, Adams 2006b, Gupta et al. 2007, Anyanwu and Erhijakpor 2010, Ajayi et al. 2009, Lu, Y., \& Treiman, D.J. 2011).

Based on the research of Yan Xing et al. remittances are often used to enhance the living standards of the individuals left behind in the homeland ( Stark,1984; Massey, 1990, 1994; Massey et al., 1993; Massey and Parrado, 1994; Semyonov and Gorodzeisky, 2004, 2008). Indeed, year by year the number of households in poor countries started to increase as migration is becoming as an economic strategy, which means more people are moving to better economy countries in search of higher earnings. In other words, labor migration has become as one of the options of living for poor households as their financial expenses became more depend on remittances for daily expenditures. The research of Micheal Carotta, revealed that migration of family member brings additional financial resources through remittances, which might improve the consumption and investment of households (Michael C. 2013). Remittances are found influencing an income stabilizing effect of both the macroeconomic level and the household level (World Bank 2006, Chami et al. 2009). From the history, remittances should improve the situation during the economic downturns and financial crises, due to efforts of people who tries to send more money to help relatives left behind (World Bank 2006b, Yang 2006, Yang and Choi 2007, Mohapatra et al. 2010). For example, in Ghana and Ethiopia households had survived the economic shock because of the cash. Spending their cash have played key moment as it let them avoidance of selling their livestock (Quartey 2006 and Mohapatra et al. 2009).

From the other side, Nguyen and Mont, (2010) researched that most international remittances go to non-poor families, so the impact of migration avoiding poorness has its frames, although a recent program contributing international migration in poor areas might begin turning the situation. Nowadays, remittances mainly go to people with middle economic wealth and living mostly in cities. Moreover, in other countries majority families getting financial resources are most likely to invest money to business with the purpose of generating more money than just spend to consumption. In addition, Nguyen and Mont stated that in "modern world" international remittances are not considered as effective measurement of poverty decreasing in short time. To climb remittances efficiency, amount of money received by poor families should be increased. Therefore, remittances help not only to poor families but also it makes some household's financial condition even more stronger.

The research of the Edward et. al (2003) found households receiving remittances spend more money on durable goods rather than on consumption, which means investments products are more preferable for remittance receiving families as there is a positive effect on capital accumulation of the household. Meanwhile, Adams (2005) revealed that remittance receiving families in Guatemala spend more money on human capital, education and health rather than consumption.

Financial resources from outside can positively affect not only daily expenses but also it can be considered as investment of migrant parent into children's education. Bryant (2005) suggested that in Philippines remittances were used to educate children on better private schools than usual public schools. He implied that if children left behind attend private schools, they have a higher probability of getting better grades than non-migrant's children. Also income as a remittance may create an opportunity to children to develop their knowledge and increase their level of education (Hanson and Woodruff 2003). 
Cox-Edwards and Ureta (2003) during their research on "Effect of migration on academic performance of children" found that additional income from remittances might decrease the need for child labor and increase children's academic performance in particular - schooling of girls in developing countries. Moreover, their study found that left behind children fared better than children who live together with parents. The result was not only related with school attendance, but also in achievements and performance. These findings suggest that additional income through remittances somehow positively influence on better outcomes of migrant's children. Almost the same findings were found by Anderson and Kroeger (2014) in their "Kyrgyzstan Integrated Household Survey".

On the contrary, movement of parents can significantly influence on school attendance of left children. According to McKenzie and Rapoport (2006) there is a negative influence of migration on children from 12 to 18 years old (boys from 12 to 18 while girls from 16 to18 year old). He highlights that children of migrants are also more likely to move to another country by making themselves as a migrant because of law human capital in US (example of Mexican children migrating to USA). Furthermore, the absence of adults at home, more likely to increase the responsibility of adult children to take care of little siblings to assist in running the household, which makes comprehensive to remain in school or colleges (Hanson and Woodruff 2003; Acosta 2006). Therefore, whether the reduction in the number of parents at home is crucial in improvement of children's education level or not. It is important to note that some researchers stated that academic outcome is directly related with parental absence (Lahaie et al., 2009; Ye and Lu, 2011) or due to the absence - left children spent more time at home by dealing with farm or in-home activities (Chang et al., 2011; Mckenzie and Rapoport; 2011) while others found there is no any relationship between migration and education of children s (Zhou et al., 2015).

Most studies were related with the overall effect of left children on educational performance and do not take into account other heterogeneous influences that can account for diversity in findings. For instance, only limited previous studies paid attention on gender of parents who migrated to another country while analyzing the impact of migration on academic performance of children (Chen et al., 2009; Antman, 2013; Wang, 2014).

Several researches on effect of migration in case of Kyrgyzstan were already done by some people previously. Abdykadyrova A. (20..) focused her study on finding correlation between labor migration and social problems. It was found that income per capita, number of old members of household and number of active men and women are correlated with the movement of household member. Another study from Kyrgyzstan was made by Aleksandr Kondratu (2013), on finding effect of migration to children and women. As a result of the study illustrated that majority men who left the household divorce with their wife with the purpose of finding "New life" abroad by putting in difficult condition as there is no source of income and even some women had to migrate to other countries by taking their children together. Also, he identified that migration of father, or divorce of parents might create inadequate condition for left behind children. The effect of migration was also studied in case of impact on elderly people by Mehrigul Ablezova (2008). It was found that due to the migration elderly people of the households are living in extreme poverty conditions in chosen two regions of Kyrgyzstan. The study was focused on how migration and remittances influence on informal transfers within social network. Preliminary result of the study revealed migrant household make more financial transfers than non-migrant households in rural area.

The crucial factor that motivated to make the study in this particular topic was lack of findings in previous researches which created some gaps that can be covered by further analysis. Previous studies covered effects of migration on social problems, left behind women and children, life condition of elderly people and informal transfers. However, effect of remittances on children's education and their further career development were not studied in the case of Kyrgyzstan. Another factor that effected on researcher's decision of conducting a research was the fact that the lack of study in effect of remittances on improvement of household condition.

\section{Research Question}

The effect of migration on household and left behind family members: Case of Kyrgyzstan

\section{Objectives}

- To analyze the life condition in terms of housing, expenditure and child education of migrant's family.

- To identify the effect of remittances on expenditure of migrant's household.

- To determine the impact of migration on child education and housing condition of migrant's family members.

\section{Methodology}

In this part, there are discussions concerning strategies, approaches, validity and reliability, data types and analysis as well as used model of regression. 


\section{Research Philosophy:}

For this research it is used secondary data, which was collected by Stockholm International Peace Research Institute in 2012 and 2013 years. Secondary data is the use of data, which is already collected by another party and can be used to test new hypotheses or answer new research questions (Doolan \& Froelicher, 2009). The research reflects the philosophy of positivism by creating a situation for researchers to work with testable and observable realities and generalize the outcome. Researches using positivism believe in constant reality, which can be observed and explained objectively (Levin, 1988). By using positivism, J. Gibson, D. McKenzie and S. Stillman (2009) made research to identify the impact of migration on remaining household members. Also Antje Kroeger (2012) addressed to positivism philosophy in his paper "Remittances and the human capital of children: New evidence from Kyrgyzstan during revolution and financial crisis, 2005-2009".

\section{Research Type and Approach:}

The deductive approach has applied to identify the effect of migration on family lifestyle as data includes the study of households in Kyrgyzstan. The deductive method begins with the general principles or truth of the believe and implementing them to the exact experiences (Carotta, 2013). Furthermore, the deductive approach might be characterized as the one, where researcher is able to look through those effects objectively and the quantitative data helps to examine the relationship between variables (Saunders et al., 2003). The result of the research will be numerical that can be later analyzed statistically and identify correlation between migration and family lifestyle. Meanwhile, deductive approach contains of quantitative research, which allows the researcher to measure and analyze data (Jones, 2017). This method was also used by Emil Nasritdinov, 2012, Nate Shenkkan, Azim Atamanov and Marrit van den Berg, 2010) in the paper named "A Portrayal of Absence: Households of Migrants in Kyrgyzstan".

\section{Research Purpose:}

Based on the literature review and lack of number of studies on relationship between migration and lifestyle, this paper is going to analyze key factors, which lead to change in life for better or worth condition due to movement of members to another country. To understand those factors deeper, it was decided to choose Kyrgyzstan because of its economic growth and level of migration after their independence. It is true that the migration became one of the important elements of Kyrgyzstan economy after its independence. There are many different ways to examine the multiple realities of migration in society, through quantitative research various effects of migration on family lifestyle can be explored. The quantitative research is a nature of explanatory research, which stands for mentioning the cause and effects between variables. The main purpose of explanatory research is to find out any causal links between the factors or variables influencing to the research problem (Dr. van Wyk, 2017). and Through this research, study can be organized properly and make the process structured. At the end, explanatory research allows to determine the nature of relationship between causal variables and effects. Meanwhile, current research method was used by A. Abdykadyrova (2016) during her research named "Household determinants of labor migration in Kyrgyzstan" and M. Abzelova, E. Nasritdinov, R. Rahimov (2008) on topic "The impact of migration on elderly people".

\section{Research Hypothesis:}

- Working outside of household member improves life condition of left behind people.

- Movement of parent's influence on education of children and daily expenditure.

\section{About Secondary Data}

The "Life in Kyrgyzstan" Study is a research based, open access, multi-topic longitudinal survey of households in Kyrgyzstan. It includes tracking of 3000 households over time in seven oblasts and two cities Bishkek and Osh. 1500 micro enterprises operate the surveyed households. Within those areas, the households were drawn by stratified two - stage random sampling. Fact finding strategies and tools such as Questionnaire and Interview were applied in data collection. Collected data can be represented at national and regional level such as East, West, North and South. The participants of the survey were adult household members who were observed on a demographics, assets, expenditure, migration, subjective well-being 'and other topics in this kind. The survey firstly conducted in 2010 and has been repeated three times during the next years $(2011,2012,2014)$. All members of the household participated in 2010 are tracked each time of the survey as well as new members were added to survey during next years and tracked as well. Based on this information it can be analyzed correlations between effects and conduct deeper study of life in Kyrgyzstan.

\section{Reliability and Validity}

\section{Face Validity}

"Reliability and validity are tools of an essentially positivist epistemology." (Watling, as cited in Golafshani 2003, p 598). Reliability might be classified as a consistent result over time and a proper illustration of the whole population under the research (Joppe, 2000). If the results of the study would be the same after several repetition of the research based on that data, then the research instrument can be considered as a reliable. The "Life in Kyrgyzstan" Study was invented by Prof. Tilman Bruck as a project established by the German Volkswagen 
Foundation during 2 years (from 2010 till 2012). The project was collaborated with such organizations as DIW Berlin, Humboldt-University of Berlin, the Center for Social and Economic Research (CASE-Kyrgyzstan), and the American University of Central Asia. Moreover, starting from 2013 till 2015 the Study was founded by other organizations as Department for International Development and International Zeolite Association as a part of the Growth and Labor Market-Low Income Country Programme by Senior Fellow in SIPRI - Prof. Tilman Bruck. Nowadays, The SIPRI is considered as lead institution, which works with University of Central Asia (Kyrgyzstan), Hannover University (Germany), Manchester University (UK), Vanderbilt University (USA), and several research institutions from Asia and Europe.

\section{Content Validity}

Validity examines to what extend the research truthfully measured, which it was planned to measure or how truthful is the outcome (Joppe, 2000). To make research valid, questions were formulated in English then translated into Kyrgyz and Russian. Moreover, they were prepared in logical manner before the survey, so the respondents will be able to follow starting from easy to more difficult questions. There were 120 recruited interviewers, who were led by 40 supervisors controlling the data quality checks and counseling. There were various types of question which helps to deeply analyze the lifestyle of not only individuals but also whole household. These questions were about children educational institutions, nearest location of medical and other types of services, expenditures on food and nonfood products, amount of remittances, occupation of household members and many other questions that related with the life of people. It is agreeably that several numbers of questions might mislead the household members and lead to confusions, however, having asked all these questions decrease the level of bias in the analyses of life condition of people. Meanwhile, During the survey, interviewers followed the similar way of asking questions from all respondents by ensuring the reliability of data collection

Objective 1. To analyze the life condition in terms of housing, expenditure and child education of migrant's family.

\begin{tabular}{|c|c|c|c|c|c|}
\hline Variable & Obs & Mean & Std. Dev. & Min & Max \\
\hline age & 10949 & 29.26121 & 17.88367 & 0 & 96 \\
\hline schoolfee & 4865 & 518.9723 & 1468.897 & 0 & 15000 \\
\hline expenseedu $\sim$ s & 4865 & 2691.591 & 2417.59 & 0 & 20000 \\
\hline repairfee & 4865 & 386.5344 & 929.6855 & 0 & 10000 \\
\hline leavingmonth & 10949 & 6.119098 & 3.241226 & 1 & 12 \\
\hline Remittances & 9509 & 51790.37 & 59597.89 & 100 & 639000 \\
\hline educationa $\sim$ expense & 10949 & 1.734222 & .4417666 & 1 & 2 \\
\hline Medexpense & 10949 & 1.75258 & .4315325 & 1 & 2 \\
\hline Wedding expense & 10949 & 1.76628 & .4232154 & 1 & 2 \\
\hline Funeral expense & 10949 & 1.879624 & .3254159 & 1 & 2 \\
\hline Investment & 10949 & 1.986848 & .1139302 & 1 & 2 \\
\hline durablegoods & 10949 & 1.724998 & .4465358 & 1 & 2 \\
\hline physiologi $\sim$ s & 10949 & 1.389077 & .487563 & 1 & 2 \\
\hline helpotherhh & 10949 & 1.969952 & .1707283 & 1 & 2 \\
\hline saving & 10949 & 1.600329 & .4898531 & 1 & 2 \\
\hline relienceon $\sim$ e & 10881 & 31.57109 & 44.46383 & 1 & 99 \\
\hline hhcondition & 10881 & 1.31964 & .4663584 & 1 & 2 \\
\hline region & 10949 & 5.479039 & 3.838235 & 2 & 21 \\
\hline
\end{tabular}

\section{Table 1 General Overview. Created by Researcher.}

From the table 1. it can be seen general information such as age, average of expenses, spending of remittances and amount of receiving money, as well as reliance of household members on remittances.

In order to analyze the effect of migration on household condition, firstly we eliminated necessary data collected in 2012. In general, it was decided to focus on 6 topics covering child education, housing, food/non-food expenditure and migration.

\section{Results}

Objective 2. To identify the effect of remittances on expenditure of migrant's household. 
Linear regression is a statistical tool which uses in predicting the value of dependent variable from explanatory variable when the relationship is described in linear model. The way that the data coefficients are found is by minimizing the errors. On the contrary, OLS coefficient of appraised model, meets issue when it is used with binary dependent variable. Squared $\mathrm{R}$ is not measured accurately to overall fit. Explanation with dependent dummy variable is not presented by $\mathrm{R} 2$ to main decision makers. Estimated equation is written as follows: $\mathrm{Yp}=\mathrm{mX}+\mathrm{b}$, where $\mathrm{Yp}$ is the estimated value of dependent variable, $\mathrm{m}$ is the slope of the line and $\mathrm{b}$ is the intercept of the regression line. It was decided to use linear regression because of numerical dependent variable. It was examined the effect of migration on food expenditure of households.

\begin{tabular}{|l|l|}
\hline Food Expenditure & OLS model \\
\hline Degree of diploma & -8.774711 \\
\hline Age & $-2.138333^{* * *}$ \\
\hline Oblast & $8.882919^{* * *}$ \\
\hline Housing type & $-58.11866^{* *}$ \\
\hline Remittances & 0.0005144 \\
\hline Period of receiving remittances & $303.3593^{* * *}$ \\
\hline Constant & -146.8663 \\
\hline Observations & 7703 \\
\hline R2 & 0.0928 \\
\hline & \\
\hline Expenditure on nonfood products & OLS model \\
\hline Degree of diploma & 14.7956 \\
\hline Age & $54.52323 * *$ \\
\hline Oblast & $237.9633^{* *}$ \\
\hline Housing type & 751.7819 \\
\hline Remittances & $0.038937 * *$ \\
\hline Period of receiving remittances & $-1338.82^{* * *}$ \\
\hline Currency & $1427.906 * * *$ \\
\hline Constant & 1264.756 \\
\hline Observations & 7703 \\
\hline R2 & 0.0126 \\
\hline & \\
\hline
\end{tabular}

Table 2 Food and Nonfood Spending

Table Y includes effect of variables on food and non-food expenditure of households who have at least one member went to foreign country with earning purposes. Total number of observations is 7703 people. It is interestingly to notice that, remittance is not statistically significant and has minor coefficient $(0.0005)$ to food expenses. Nevertheless, although it seems basic, period of receiving money has strong significant impact on food expenses and every increase in period of receiving money, we expect to 303.4 increase in log-odds in food expenses. It Is interestingly to note that, period of receiving money is statistically significant and each increase in frequency of receiving money might lead to increase for 303.35 expenditure on food with $95 \%$ of confidence level, which exemplifies that as household receiving money frequently as much their condition in food expenditure is better. On the other hand, every enhancing in housing type of the household for better condition, we expect 58.11866 decrease in food expenses keeping other variables constant. The reason might be related with increase in amount of rent, tax or loan from financial institutions and others.

When it comes to results of the migration on non-food expenses, it can be seen that there is relative difference as compared to food expenses. For instance, the coefficient of degree of diploma of left member 3 times (negative) less than effect on food expenses. However, it is seen that unit change in housing type, we expect 751.78 increase in log-odds in non-food expenses although it is not statistically significant. Nonetheless, effect of remittances is strongly significant and by receiving more money, 0.04 coefficient increase in non-food expenses is expected.

Objective 3. To determine the impact of migration on child education and housing condition of migrant's family members.

\section{Child education}

The aim of this paper is determining the effect of migration on child education and following model is used:

$\mathrm{L}: \operatorname{Pr}\left(\mathrm{Ch}_{i t}=1\right)=\ln \left(\frac{\mathrm{Chi}}{[1-\mathrm{Chi}]}\right)=\beta 0+\beta 1$ Remittance $_{i t}+\beta 2$ Age $_{i t}+\beta 3$ Region $_{i t}+\beta 4$ Language $_{i t}+$ $\beta 6$ absenceofhhmember ${ }_{i t}+\beta 7$ followed additional migrant member mit $+\varepsilon_{i t}$.

$\left(\mathrm{CH}_{i t}=\alpha+\beta X_{i t}+\varepsilon_{i t}\right)$ where Ch stands for Child education of household member. X's are explanation characteristics of estimated impacts. The error term captured to avoid the missing measurement errors. 
Since the using dependent variable (education status of children) is categorical, and to regress the model it is required to use Logit model, because Ordered logit is not suitable due to dummy dependent variable. Meanwhile, As Ai and Norton (2003) suggested, the results produced by ordered probit regression is more likely challenging in interpretation of coefficients than commonly assumed.

\begin{tabular}{|l|l|}
\hline Child education & Logit model \\
\hline Remittance & $5.75 \mathrm{e}-06 * * *$ \\
\hline Age & $-.0042004(\mathrm{P}=0.22)$ \\
\hline Region & $-0.1101339^{* * *}$ \\
\hline Language & $0.8466678^{* * *}$ \\
\hline Housing Type & $-0.2124902 * * *$ \\
\hline Absence of hh member & $0.3827104 * * *$ \\
\hline Recipients & $1.567725^{* * *}$ \\
\hline Constant & -3.1506 \\
\hline Observations & 4863 \\
\hline Pseudo R2 & 0.021 \\
\hline
\end{tabular}

Table 3 Child Education

$* \mathrm{P}<0.1 ; * * \mathrm{p}<0.05 ; * * * \mathrm{p}<0.001$

Based on the results of the table, it can be said, in general there is a significant impact of being migrant on education of children. Analysis were done with 5494 participants and in general effects of explanatory variables $5.1 \%$ effects on child education while other $95 \%$ effects from outside sources. Basically, every increase in amount of remittances lead to 5.75 increase in log odds of child education. The same analysis was done by Davide Mckenzie in his research "effect of migration of educational attainment" and it was identified that remittances has significant impact on education of left behind children. Regardless the fact that Davide Mckenzie's research was done in Mexico, the discovered result is identical with results of Kyrgyzstan. Moreover, controlled variable Age was added to find out more effective impact of variables on child education. It is interestingly that "Age" is not statistically significant to child education and each increase in age, it is expected to decrease the child education $\log$ odds for -.004 . The coefficient for the independent variable housingtype is negative $(-0.2124902)$ and moving from barracks to separate parts of house, it is expected a (0.2124902) decrease in the log-odds of the dependent variable education status, keeping all other independent variables constant. Furthermore, the representing coefficient of recipients is 1.567725 and $\mathrm{P}$ equals to 0 . It is statistically significant that for one-unit increase in receiving money, it is expected to increase for 1.57 increase in the education status. It is statistically significant that every year increase in age, lead to 0.005 increase in the log-odds of education status of children. Therefore, based on the analysis it can be said that the migration has significant impact on education of children.

\section{Housing}

\begin{tabular}{|l|l|l|l|}
\hline & Separate apartment & Separate house or part of it & $\begin{array}{l}\text { Barracks } \\
\text { Y=3 }\end{array}$ \\
\hline & Y=1 & Y=2 & Base outcome \\
\hline School fee & 0.0012 & 0.001 & \\
\hline Expense on education supplies & $-0.00075^{* * *}$ & $-0.00095^{* * *}$ & \\
\hline Repair fee & $0.0052^{* *}$ & $0.008^{* * *}$ & \\
\hline Food expense & $0.00015^{*}$ & $0.0015^{* *}$ & \\
\hline Nonfood expense & $-2.05 \mathrm{e}-06$ & 0.00003 & \\
\hline Diploma degree & $1.12^{* * *}$ & $0.9999^{* * *}$ & \\
\hline Activity sector & $0.32 * * *$ & $0.3530^{* * *}$ & \\
\hline Remittances & $-2.0273^{* * *}$ & $-1.8934 * * *$ \\
\hline Age & $0.087^{* * *}$ & $0.07597^{* * *}$ & \\
\hline Region & $2.3535^{* * *}$ & $2.3025^{* * *}$ & \\
\hline Cons & -10.19342 & -7.9162 & \\
\hline Observations & 3350 & & \\
\hline Pseudo R2 & 0.2021 & & \\
\hline
\end{tabular}

\section{Table 4 Housing}

Table 3 illustrates the Multinomial regression coefficients as well as standard errors. Second and third columns represent the outcome of independent variables. Forth column (Barracks) type of house is taken as base outcome for current regression model. Looking at the table, it can be seen some surprisingly results. School and nonfood expenses do not have statistical significance level in housing. Furthermore, expenses on education and remittances have negative relation with housing type of migrant's family. As for researcher it was surprisingly that increase in 
amount of remittances, it is assumed 2.0273 and 1.8934 decrease in log-odds of separate apartment and separate part of house respectively. Another independent variables degree of diploma and activity sector of migrants has more likely to expect positive connection with housing type of left household members. The other variables reveal the expected prediction of impacts on housing of households.

In general, the paper discovers living condition of family members experiencing migration within the households. To reach the goal secondary dataset was drawn, which includes information of thousands of observers. In finding analysis, regression estimated models was used for all dependent variables separately and conducted special tables for clear understanding. Family members of migrant's is more dependent on remittances and more than $65 \%$ of participants stated their dependency on those money, to stabilize or enhance life condition of all members (starting from child to parent). When Stata software measured the impact of remittance, increasing amount has positive probability on child education and nonfood expenses while negative impact was seen in food expenses.

\section{Conclusion}

More than billion international and internal migrations around the world as well as the relationship between migrant and its family members have been the most discussed policy questions for many years. From the beginning, labor migration is considered as economically benefiting to left household members. In particular, remittances might benefit to budget constraints of households and thereby expenses on education, enhancement of household's welfare and other valuable things in this kind. Nonetheless, absence of household member might have negative impact on left behind loved ones. The purpose of the paper is to investigate potential impacts of labor migration in Central Asian countries and Kyrgyzstan was chosen as a base. Results of the research illustrates high dependency on remittances and some negative impact on child labor issues of households. Moreover, the decision of labor migration in Kyrgyz families is not connected with real need, but it is more related with fashionable trend among citizens of Kyrgyzstan. However, in reality the number of migrants regularly sending money and crucially improving the life of left behind people is very small, while majority migrants help loved ones just to exist by experiencing difficulties, damaging their health and limiting themselves of earning money within their country as well as experiencing isolation from family members and emotional distress. However, it was identified positive effects too, especially for children, and economically better life condition. As the results of manipulation with variables in statistical analysis revealed, the migration has positive impact on education of children. Migrant's children might be provided with better economically condition which allows them to go to school, pay for additional tutoring or studying at private schools by getting high quality education. Otherwise, poor economic condition might decrease the opportunity of education of children because of working in the backyard or taking care of siblings while mother/left member of household is working.

Meanwhile, according to recent economics of labor migration, decision of migrating more related with household decision as compared to individual one in developing countries. Hence, linear regression and multinomial regression models were used to see the impact of migration on household living condition and its consequences. As a result, it was identified that migration and remittances provide better condition for child education, also it has positive effect on food and nonfood expenses. About $89 \%$ of migrant's children enrolled to educational institutions in particular, $97 \%$ of them study at school while $2 \%$ at universities. School aged people feel financial support from the outside of the country and there is no need to find job at this stage of their life. According to previous research effect of migration on children by McKenzie and Rapoport (2006), children of migrant's is more likely to migrate to another country by leaving their homeland while they need to study at school. However, In Kyrgyzstan 99.7\% children attending educational institutions as usual and the rest missed the school due to illness $62 \%$ and working to support family $20 \%$. Moreover, Ekawati S. Wahyuni (2005) identified that children of migrants were sent to village to be cared with grandparents and go to school while mother is working in the city and support its family. His findings exemplify that not all migrants are able to support family members by sending remittances, instead it leads to isolation of children from parents. Also he identified that migrant's family members in Bandung is more likely to share room with some people to save on living costs, while result of my research in case of Kyrgyzstan migrants, revealed that majority percentage of sample live either in purchased or build homes. Furthermore, it is seen positive effect on spending of households. Remittance receiving household on average spend 3600/month Som to education of children such as fee, tutoring and educational supplies. Additionally, 63\% (6772 obs) households build their own home while 23\%(2390 obs) purchase new living apartments. Likewise, presence of diploma or higher education level has significant positive impact on housing of household members. As higher the degree of diploma of migrants, as better opportunity for earning more money abroad and improve the living wealth of family members. The reliance of household members as compared to last year was same for $38 \%$ respondents and $25 \%$ felt face more reliance on remittances to cover daily and long term expenses. As a result of the survey, households having low income per capita are more likely to choose the migration to abroad by pursuing various job places. $68 \%$ of 10881 observers believe that migration and remittances improve the health and/or education of household members. The result of the current research found identical with some paper's result (Bennet et al., 2010, Yabiku et al,. 2012, Meng et al., 2015) who examined 
positive effect of migration on school attendance of migrant's children. When it comes to the personal view of researcher, it is believed that migration has both positive and negative impact on left behind people. From context of regulating such outflow of people, it is necessary to create the policy that will emphasize migration conditions. Indeed, there are people who are really experiencing difficulties to survive or those who are living in rural areas and allowing them to work and earn money will be from the side of honesty. At the same time, such policies will control the outflow of people, as well as engage people to work and survive in their homeland and earn those money staying with family members if they try to do so, before looking for migration option. Taking into account positive and negative factors of migration it can be offered some recommendations to further consideration:

Firstly, the Government of Kyrgyzstan should pay high attention on keeping citizens inside the country and should consider about shifting its policies which encourage labor migration, instead it should pay more attention on development of small and medium enterprise supporting method, which actually helps to create several number of job positions. Such change in policy might decrease the dependency on remittances and encourage migrants to return back and work there. It will beneficial for both Government and citizens.

Secondly, government agencies should take as much as possible benefits from migrants. It should pay attention on enriching the qualification of labor migrants working abroad, so government will be able to acquire production and organizational skills, leading to increased efficiency and productivity in the future. Unfortunately, the majority part of Kyrgyz population has low qualification level. Moving and living in country with more advanced technologies, higher requirements for production process, higher labor standards, increases in general educational and cultural level of migrants, they have good opportunity to gain valuable experience and knowledge which can be useful in their homeland.

\section{Final Chapter}

Unexpected result obtained from estimated model of regression. Particular goals were not fully covered and explained. For instance, migration of parents might lead to moving of whole family to another country which changes the life condition of people dramatically. It was found that degree of diploma has negative impact to expenditure of household, however the adequate person more the opportunity to work for better places and earn more money. Remittances was seen in negative relation with housing type, while it was one of the main sources of improvement of condition.

To overcome the such misunderstandings, some recommendations can be suggested: merge all necessary information about household and individual dataset to more accurate analysis. Also compare life condition of migrants and nonimmigrant's family members so it might be created a picture with more accurate and clear difference between those families. Meanwhile, it can be suggested to consider about including other variables and ponder about issues included in limitation part to reanalyze possible effects of migration to households' life condition.

Although the aim of the paper conducted to identify the overall effect of migration on household living condition, there are some limitations in regression and methodology, which might impact on final result of the analysis. During regression analysis, independent variables were not much powerful as it wants the researcher. In fact, there were logical connection between variables, but according stata analysis it was given another result; therefore some independent variables were not added. in case of proper application of those variables or right execution of dependent variable, the result of the survey might differ from my findings.

It is important to recognize that the analysis of the labor migration effects on household living condition faces some methodological challenges. For instance, due to the fact migrant often countries facing economic growth and developed labor market, both fluctuation in wage and employment can be caused by immigration which makes complex to establish causality. Another issue for migrants might be leaving the place of working due to governmental regulations or some other causes, so migrant have to leave the country or move to another region of the country, it will create some complexity for migrants due to lack of knowledge about new area and lack of money. Happening such situation, effects on labor market of not only particular area but trace can be seen across the country, which makes difficult to measure the labor market correctly.

One challenge faced in methodology part due to huge data set and knowledge of no information about its collection. Moreover, dataset contained too many information about household and individuals, and it was difficult to eliminate that information which I wanted to use. There was high risk of eliminating useful information.

Another limitation might be connected with usage of Stata software. In fact, we were thought various useful tests, however, due to lack of time, I was able to use only few of them. Application of more tests might create more interesting atmosphere for readers of the paper and give more impression about findings. Moreover, it was possible to merge information of households with individuals, it would be more powerful and even more interesting results can be reached. If there was a chance to work one more time on dissertation, I would definitely choose the same topic but focus on another impacts of migration. 


\section{References}

- A Portrayal of Absence: Households of Migrants in Kyrgyzstan. (2012). Phd. SIAR research \& Consulting.

- Adams, Richard H., and Alfredo Cuecuecha. "Remittances, household expenditure and investment in Guatemala." World Development 38, no. 11 (2010): 1626-1641. Available at: https://www.openknowledge.worldbank.org/handle/10986/5203 [Accessed 5 Feb. 2018].

- Bespalov D.A (2009) “Analysis of remittances and their impact on GDP of Kyrgyz Republic"; Vestnik KRSU; 2009, \#8, p36. Available at: http://www.os.X-pdf.ru/20raznoe/155814-3-almaty-kazakhstan-11-13october-2012-international-conference-e.php [Accessed 10 Feb. 2018]

- Edwards, Alejandra Cox, and Manuelita Ureta. "International migration, remittances, and schooling: evidence from El Salvador. "Journal of development economics 72, no. 2 (2003): 429-461. Available at: http://www.nber.org/papers/w9766 [Accessed 5 Feb. 2018].

- Human migration: concepts and approaches. (2005). [ebook] Sinha B.R.K, pp.1-12. Available at: http://www.mtafki.hu/konyvtar/kiadv/FE2005/FE20053-4_403-414.pdf [Accessed 13 Nov. 2017].

- Kroeger, Antje, and Kathryn H. Anderson. "Remittances and the human capital of children: New evidence from Kyrgyzstan during revolution and financial crisis, 2005-2009. "Journal of Comparative Economics 42, no. 3(2014): 770-785. Available at: https://ideas.repec.org/a/eee/jcecon/v42y2014i3p770-785.html [Accessed 5 Feb. 2018].

- $\quad$ Lu, Y., \& Treiman, D.J. (2011). Migration, remittances and educational stratification among blacks in apartheid and post-apartheid Sourth Africa. Social Forces, 89(4), 1119-1143. Available at: https://www.ncbi.nlm.nih.gov/pmc/articles/PMC3736599/ [Accessed 10 Feb. 2018]

- Lu, Y., \& Treiman, D. J (2012). Education of children left behind in rural China. Journal of Marriage and Family, 74(2), 328-341. Available at:

https://reap.fsi.stanford.edu/sites/default/files/303_effect_of_parental migration_on_the academic perform ance_of_left-behind_children_in_northwestern_china.pdf [Accessed 10 Feb. 2018]

- $\quad$ "Ratha, Dilip; Mohapatra, Sanket; Scheja, Elina. 2011. Impact of Migration on Economic and Social Development : A Review of Evidence and Emerging Issues. Policy Research working paper ; no. WPS 5558. World Bank. (C) World Bank. https://openknowledge.worldbank.org/handle/10986/3328 License: CC BY 3.0 IGO. ”

- Schuler, Martin. "Migration patterns of the population in Kyrgyzstan." Escape populations societies. Space populations societies 2007/1 (2001): 73-89. Available at: http://www.zora.uzh.ch/120901/1/2015_Hatcher_20152477.pdf [Accessed 8 Feb. 2018]

- $\quad$ Team, F. (2014). 3 Types of Survey Research, When to Use Them, and How they Can Benefit Your Organization! - FluidSurveys. [online] FluidSurveys. Available at: http://fluidsurveys.com/university/3types-survey-research-use-can-benefit-organization/\#comment-2012 [Accessed 13 Nov. 2017].

- The Definition of Migration and its Application: Making sense of recent South African Census and Survey Data. (1999). SA Journal of Demography, 7(1), pp.19-21.

- Understanding Reliability and Validity in Qualitative Research. (2003). [ebook] Toronto: University of Toronto. Available at: http://www.nova.edu/ssss/QR/QR8-4/golafshani.pdf [Accessed 13 Nov. 2017 ].

- Understanding Reliability and Validy in Qualitative Research. (2003). 12th ed. [ebook] Toronto: University of Toronto, pp.597 - 602. Available at: http://nsuworks.nova.edu/cgi/viewcontent.cgi?article=1870\&context=tqr [Accessed 13 Nov. 2017].

- Web.mnstate.edu. (2005). Cite a Website - Cite This For Me. [online] Available at: http://web.mnstate.edu/robertsb/308/Introduction\%20to\%20Migration.pdf [Accessed 13 Nov. 2017].

- $\quad$ Xing, Y., Semyonov, M. and Haberfeld, Y. (2015). Chapter 21 Labor Migration, Remittances, and Economic Well-Being: A Study of Households in Rajasthan, India. [online] Emerald. Available at: http://dx.doi.org/10.1108/S1574-8715(2010)0000008027 [Accessed 13 Nov. 2017].

- (2002),"Regulating women and managing men: Regimes of control on Languedoc family enterprises", Research in Economic Anthropology, Vol. 21 pp. 163-186 